\title{
Oral Hygiene and Gingival Status of Children with Down Syndrome in A University Hospital Setting - A Retrospective Analysis
}

Research Article

Lakshya Rani $\mathrm{S}^{1}$, Mebin $^{2 *}$, G. Maragathavalli ${ }^{3}$

${ }^{1}$ Graduate Student, Saveetha Dental College And Hospitals, Saveetha Institute Of Medical and Technical Sciences, Saveetha University, Chennai,600050, India.

${ }^{2}$ Senior Lecturer, Department of Pedodontics, Saveetha Dental College and Hospitals, Saveetha Institute Of Medical And Technical Sciences, Saveetha University, Chennai, India.

${ }^{3}$ Professor, Department of Oral medicine, Saveetha Dental College and Hospitals, Saveetha Institute Of Medical And Technical Sciences, Saveetha University, Chennai, India.

\section{Abstract}

\begin{abstract}
Down Syndrome (DS) is the most common chromosomal disorder in which an extra copy of chromosome will be present in chromosome 21. Periodontal diseases are inflammatory diseases of supporting structures of the teeth. Gingivitis and periodontitis start early in life in DS individuals and their severity increases with age. This study aimed at evaluating the oral hygiene status of children with down syndrome in a university hospital setting. This study is a Retrospective study conducted in a University hospital setting. The study population consists of 19 children with Down syndrome who had reported to Saveetha Dental College and Hospitals, Chennai, India. The data regarding the age, gender and clinical parameters like $\mathrm{OHI}$ and gingival index were retrieved from patients records and analysed. After the fulfillment of inclusion and exclusion criteria, a final sample of 19 children were considered.The data were tabulated and analysed by SPSS software and statistics done using Chi Square test with significance kept at $\mathrm{p}<0.05$. From the present study, it is observed that the majority of the study population with Down syndrome was found to be within the age group of 3-9 years (57.8\%) and males dominated the study population when compared to females. The oral hygiene status was found to be moderately good in the majority of the patients in the age group between 3 - 9 years (52.6\%). Majority of the children in the age group between 3-9 years $(42.1 \%)$ were found to have moderate gingivitis and majority of the children within the age group of 10 - 17 years $(5.2 \%)$ showed severe gingivitis. Within the limits of our study, it was observed that the majority of individuals with Down syndrome maintain oral hygiene fairly and hence have moderate gingivitis.
\end{abstract}

Keywords: Down Syndrome; Gingival Status; Plaque; Oral Hygiene Status; Periodontitis.

\section{Introduction}

Down Syndrome (DS) is an autosomal chromosomal anomaly associated with trisomy of chromosome 21 [1]. It is characterized by the whole chromosomal aneuploidy in about $95 \%$ of the cases. The remaining $5 \%$ is in the form of translocations and mosaics [2]. Down Syndrome is the common genetic birth defect, affecting approximately one in 700 live births [1] According to the National Down Syndrome Society (NDSS) more than 400,000 individuals with DS live in the United states. Moreover, life expectancy for DS patients increased dramatically in recent decades, from 25 years in 1983 to 60 years today [3].
The most common manifestations of the syndrome are mental retardation, and a variety of morphological characteristics [4]. Down syndrome is a congenital autosomal anomaly affecting 1 in 600 to 1 in 1000 live births [1]. Approximately 40\% of infants with Down syndrome suffer from heart disease and 1 in 200 children are present with leukemia (mostly the acute lymphocytic type) [5]. Furthermore, children with Down syndrome feature growth retardation, hormonal disturbances, obesity and neuropsychiatric disorders [6]. They have also increased susceptibility to infection due to impaired host response characterized by reduced chemotaxis, impaired phagocytosis, and disturbances in T- and B-cell subpopulations [7]. Some of the oral conditions associated with Down syndrome are:"V" shaped palate, lower lip

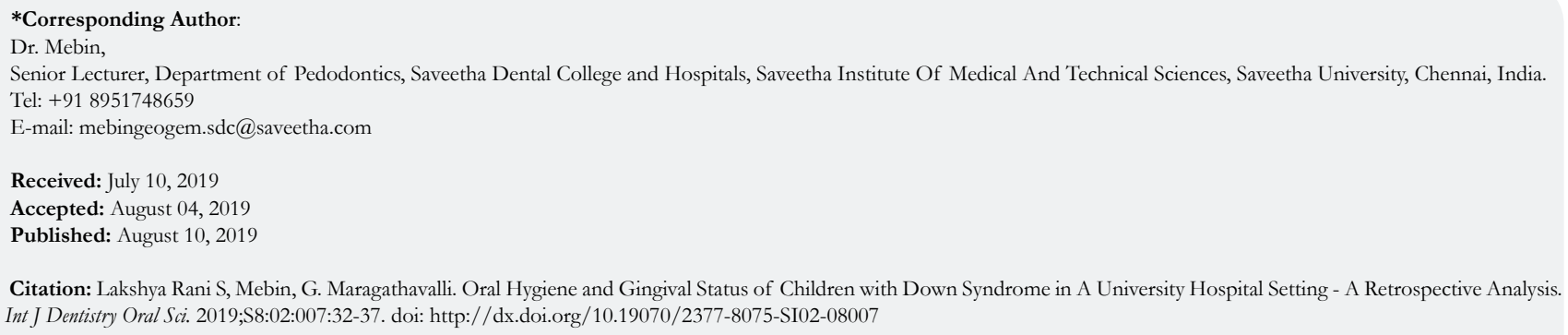

Copyright: Mebin 2019. This is an open-access article distributed under the terms of the Creative Commons Attribution License, which permits unrestricted use, distribution and reproduction in any medium, provided the original author and source are credited. 
everted, mouth breathing with drooling, angular cheilitis, fissured tongue, microdontia, hypodontia, taurodontism, delayed eruption, spacing, bruxism and periodontal disease [4].

Patients with Down syndrome have certain anatomical abnormalities along with mental and orofacial problems that affect the quality of life [3]. Furthermore, DS patients are more susceptible to infections including an increased prevalence of periodontal diseases, almost $100 \%$ under the age of 30 years [8]. Periodontal disease in these patients is severe, generalised, with rapid progression and classified as a manifestation of systemic diseases associated with genetic disorders by American Academy of Periodontology [2]. Poor oral hygiene per se may not explain severe and generalised periodontal destruction observed in DS patients. This condition is also associated with impairment of the immunological system $[9,10]$.

One of the most frequently encountered oral diseases observed in Down syndrome is poor periodontal health or gingivitis in particular, which is defined as inflammation of the gingiva caused by plaque retention on the surface of tooth structure, without the loss of attachment in the periodontal apparatus [11, 12]. In assessing the severity of gingivitis, the Gingival Index by Loe and Silness is usually employed [13]. In Down syndrome, there are two most influential factors affecting the health of periodontal tissues, particularly related to gingivitis; the first is systemic factors, such as neutrophil dysfunction, lymphocyte $\mathrm{T}$ dysfunction, increased inflammatory mediators, and hyperinnervation of the gingiva, and the second are local factors, such as poor oral hygiene, mouth breathing, tooth morphology, and plaque microflora composition [5]. Moreover, some local disorders are related to the development of early periodontal disease, such as poor occlusal correlation, high frenum insertion, early mucogingival problems and advanced tongue position [14]. In addition to periodontal treatment DS patients must receive attention and management of dental caries, malocclusion and obstructive sleep apnea [15]. The aim of this study was to assess the oral hygiene status of children with down syndrome in a university hospital setting.

\section{Materials and Methods}

\section{Study setting and sampling}

This study was a single- centred retrospective study, carried out in a private dental college. The present study was approved by Institutional ethical committee [IEC] (Ethical approval number: SDC/ SIHEC/2020/DIASDATA/0619-0320) and was in accordance with the ethical standards that were stipulated. All available records of patients from June 2019 - April 2020 were examined and a total of 86000 case sheets was reviewed. Patients below 18 years and those with DS were included in the study. Those who visited outside the time frame, with any other disorder and older than 18 years were excluded from the study. Cross verification of data for error was done by presence of additional reviewers and by photographs evaluation. Two examiners were involved in the study. Any patient with incomplete data was excluded from the study.

\section{Data collection}

Acquisition of data was done from the hospital database which records all patient details. The study included 19 children with
Down syndrome. The collected data were grouped based on the parameters of periodontal diseases. Age was categorised into 3 - 9 years, 10 - 17 years. Gender was categorised into males and females. The parameters of periodontal diseases were grouped as OHI [16] and gingival index [17]. The data were entered in the system in a methodical manner. For this study, data regarding age, gender and parameters like $\mathrm{OHI}$, plaque and gingival index were collected. The data was then entered in excel manually and imported to SPSS for analysis. Incomplete or censored data were excluded from the study.

\section{Statistical Analysis}

The statistical analysis was done using SPSS software (SPSS version 21.0, SPSS, Chicago II, USA). Descriptive statistics was used to summarise the demographic information of the patients included in this study. Descriptive statistics is used for the acquisition of frequency distribution of the data. Chi-square test was applied to analyse the association of different variables. Statistical significance was kept at $\mathrm{p}<0.05$.

\section{Results and Discussion}

The study population consists of 19 children in the age group between 3 - 17 years. Based on the distribution of the study population by age, $52.8 \%$ of the study population were found between the age group of $3-9$ years and $42.1 \%$ of the study population were in the age group of $10-17$ years (Figure1). Based on the distribution of study population by gender, $52.6 \%$ of the population were found to be females and $47.3 \%$ of the study population were found to be males (Figure 2). Based on the oral hygiene status among the study population, $21 \%$ of the children were found to have good oral hygiene, $73.7 \%$ of the children were found to have fair oral hygiene and $5.2 \%$ of the children were found to have poor oral hygiene (Figure 3). Based on the gingival status of the study population, $36.8 \%$ of the children were found to have mild gingivitis , $57.8 \%$ of the children were found to have moderate gingivitis and $5.2 \%$ of the children were found to have severe gingivitis (Figure 4).

Based on the association of age and OHI, the oral hygiene status was found to be fair in the majority of the patients in the age group of 3 - 9years $(52.6 \%)$ and majority of the children within the age group of $10-17$ years $(5.2 \%)$ showed poor oral hygiene. However,it is statistically not significant $(\mathrm{P}>0.05)$ (Figure 5). Based on the association of gender and OHI.Majority of the children with fair (36.8\%)oral hygiene status were found to be in both males and females $(\mathrm{P}>0.05)$ (Figure 6$)$ Hence there is no association between age groups, gender and OHI.

Based on the association of age and gingival index, Majority of the children in the age group between 3 - 9 years (42.1\%) were found to have moderate gingivitis and majority of the children within the age group of $10-17$ years $(5.2 \%)$ showed severe gingivitis. However, it is statistically not significant $(\mathrm{P}>0.05)$, hence there is no association between age and gingival index (Figure 7). Based on the association of gender and gingival index,Majority of the children with moderate $(31.5 \%)$ and severe $(5.2 \%)$ gingivitis were found in females However, it is statistically not significant ( $\mathrm{P}>0.05)$. Hence there is no association between gender and gingival index. (Figure 8). This study aimed to determine the fre- 
Figure 1. Bar chart represents the distribution of the study population by age. The $\mathbf{X}$ axis denotes the age group of the children with down syndrome and the $\mathrm{Y}$ axis denotes the percentage of children with down syndrome. From the graph, it is observed that the incidence of with Down syndrome is more within the age group of 3- 9 years $(57.8 \%)$ when compared to the other age group.

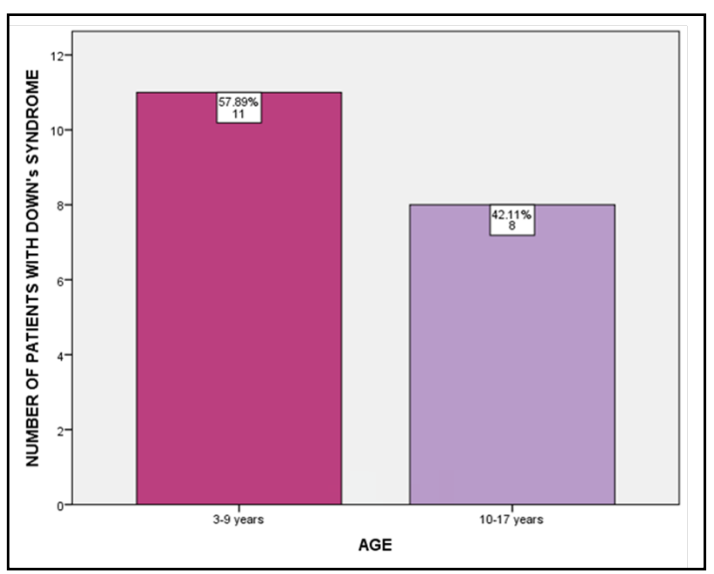

Figure 2. Bar chart represents the gender distribution of the study population. The $\mathbf{X}$ axis denotes the gender of the children with Down syndrome and the $\mathrm{Y}$ axis denotes the number of children with Down syndrome. From the graph it is observed that the incidence of children with Down syndrome is more prevalent among females(52.6\%) when compared to males $(47.3 \%)$.

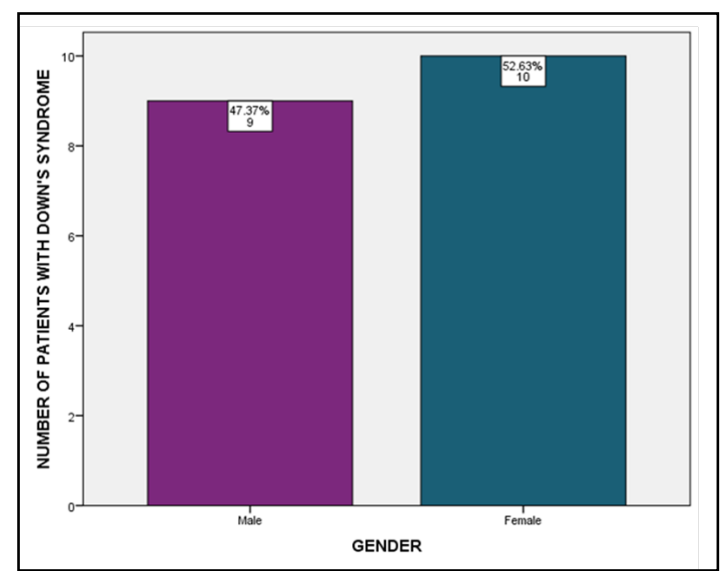

Figure 3. Bar chart represents the OHI score of the study population.. The $\mathrm{X}$ axis denotes the OHI-S interpretation and $\mathrm{Y}$ axis denotes the number of children with Down syndrome. From the graph, it is observed that the majority of the children were found to have fair $(\mathbf{7 3 . 6 \% )}$ oral hygiene status.

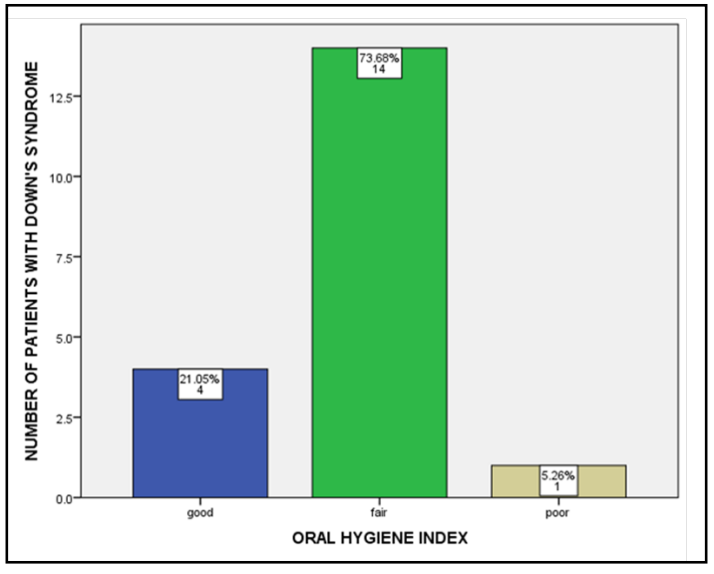

quency distribution and association of $\mathrm{OHI}$, gingivitis and plaque index in the individuals with Down syndrome of age between 3 - 17 years.

The vast majority of patients in our study (57.8\%) had moderate level of gingivitis, which is explained by the microflora composition in the subgingiva of individuals with Down syndrome compared with that in healthy individuals [18]. Alternately, host response in these individuals is dysfunctional, which predisposes these patients to gingival conditions [9]. Previous research showed that patients with Down syndrome have a higher GI than healthy controls, with a mean standard of 0.9 in Down syndrome and 0.7 in healthy individuals, with a significant difference between the two groups. This indicates a more severe level of gingivitis in 
Figure 4. Bar chart represents the Gingival index score of the study population.. The $\mathrm{X}$ axis denotes the Gingival index interpretation and $\mathrm{Y}$ axis denotes the number of children with Down syndrome.. From the graph, it is observed that the majority of the patients were found to have moderate $(57.8 \%)$ gingival status.

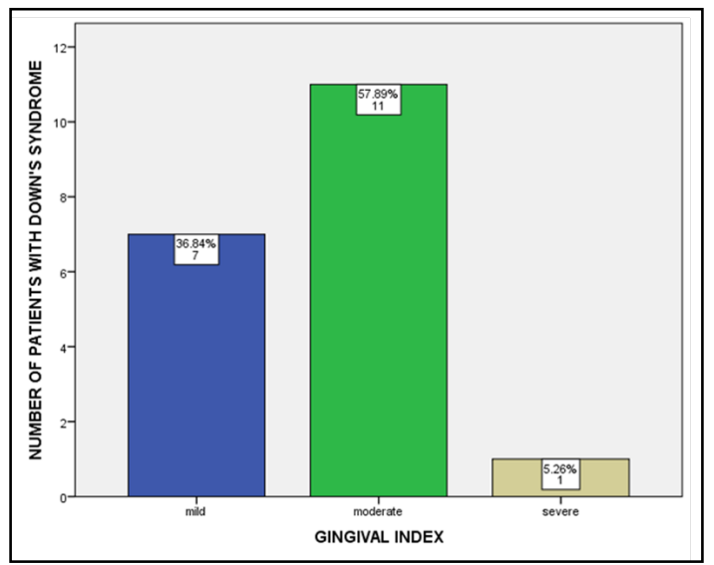

Figure 5. Bar chart represents the association between the age group and OHI-S interpretation. $\mathrm{X}$ axis denotes the age group of the children and $\mathrm{Y}$ axis denotes the number of children with Down syndrome. The oral hygiene status was found to be fair in the majority of the patients in the age group between 3 - 9 years $(52.6 \%)$ and majority of the children within the age group of $10-17$ years (5.2\%) showed poor oral hygiene. However, it is statistically not significant. (Chi-square test, $p$ value- 0.122 ( $P>0.05$ which is statistically not significant)).

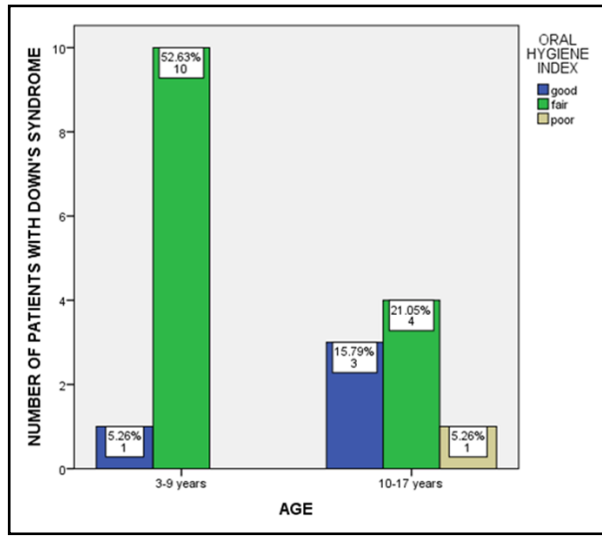

Figure 6. Bar chart represents the association between the gender and OHI. $\mathrm{X}$ axis denotes the gender of the children and the $\mathrm{Y}$ axis denotes the number of children with Down syndrome. Majority of the children with fair (36.8\%)oral hygiene status were found to be in both males and females However, it is statistically not significant. (Chi-square test, $p$ value- 0.622 ( $P>0.05$ which is statistically not significant)).

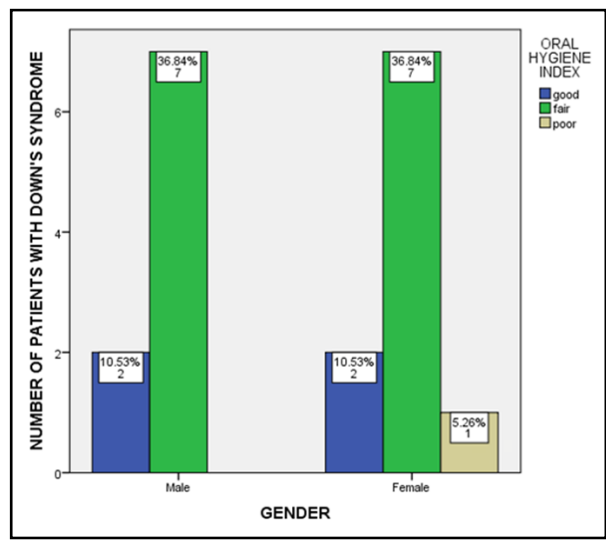

individuals with Down syndrome compared to healthy subjects and subjects with other developmental disorders [19]. Similar results were found in a previous study conducted in Temanggung, Central Java,which found gingivitis in all subjects [20]. Systemic disorders in individuals with Down syndrome can generally manifest as oral conditions, particularly in the periodontal tissues. For example, lymphocyte T-cells and neutrophil cells are dysfunction- al in Down syndrome, which subsequently exacerbates gingival inflammation response $[21,22]$.

In our study, the majority of subjects were in the mild $(36.8 \%)$ and moderate $(57.8 \%)$ gingivitis category, which is consistent with the finding in a previous study conducted in Mexico that compared a Down syndrome group with a sex- and age-matched 
Figure 7. Bar chart represents the association between the age group and Gingival score . X axis denotes the age group of the children and $\mathrm{Y}$ axis denotes the number of children with Down syndrome. Majority of the children in the age group between 3 - 9 years $(42.1 \%)$ were found to have moderate gingivitis and majority of the children within the age group of 10 17 years $(5.2 \%)$ showed severe gingivitis. However, it is statistically not significant. (Chi-square test, $\mathrm{p}$ value- 0.221 ( $P>0.05$ which is statistically not significant)).

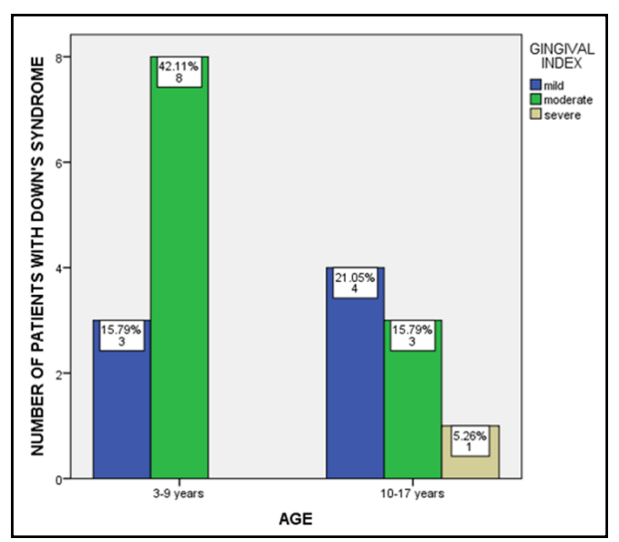

Figure 8. Bar chart represents the association between the gender and Gingival index. $X$ axis denotes the gender of the children and the $\mathrm{Y}$ axis denotes the number of children with Down syndrome. Majority of the children with moderate (31.5\%) and severe (5.2\%) gingivitis were found in females However, it is statistically not significant. (Chi-square test, $\mathrm{p}$ value- 0.553 ( $P>0.05$ which is statistically not significant)).

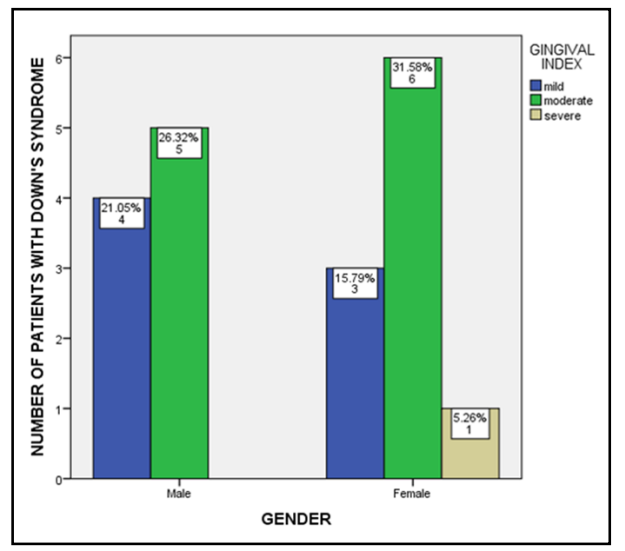

healthy control group and found that the Down syndrome group had more severe and extensive gingivitis (94.4\%) than the control group $(89.9 \%$ ) [23]. It is possible that the higher prevalence of gingivitis in Down syndrome reflects reduced motor ability, which would be a challenge to maintain dental hygiene or reduced access to dental treatments for the special needs population [23]. A study conducted in Yemen indicated a different result finding that moderate gingivitis has the highest prevalence (47.5\%), compared with the prevalence of mild (28.7\%) and severe (23.8\%) gingivitis, in Down syndrome [24], which is similar with the findings in our study. In contrast, the Temanggung study concluded that $100 \%$ of the subjects had mild gingivitis [5].

The present study revealed that the overall oral hygiene status of the study population was poor with prevalence rates of $21 \%$, $73.6 \%$, and $5.2 \% \%$ for good, moderately good, and fair components, respectively, [Figure 3] which are similar to the values reported in a previous study conducted on mentally disabled children attending special schools in Udaipur, India [25]. The reasons for this may include the reduced manual dexterity of the participants, joint laxity, and lack of comprehension of oral hygiene needs due to mental difficulties. They, therefore, need help to carry out routine oral hygiene measures. No significant difference was found in the oral hygiene scores between male and female subjects, which is in agreement with previous studies [26]. This finding implies that disability in DS children is the dominantly influential factor affecting oral hygiene, rather than gender. The present study also showed steady increase in oral hygiene scores with age, which conforms to previous reports [26, 25]. This is due to the accumulative effect of plaque and calculus with age [25]. There was also a definite trend for gingival disease as age increased, which could be explained by the same reason.

In our study, OHI and gingival index score demonstrated early signs of periodontal diseases. These results are not in concordance with a study done by Hennequin et al., [27] and NizarAhmed et al., [28] where only plaque score and OHI was taken and concluded that most of the patients had chronic periodontitis. Previously our team had conducted numerous clinical trials [29-35] and lab animal studies [36-40] and in vitro studies over the past 5 years [41-43]. The limitation of study could be smaller staple size. However, future scope of the study will focus on greater sample size with various ethnicities for establishing better results.

\section{Conclusion}

Within the limits of our study, it was observed that the majority of individuals with Down syndrome have fair oral hygiene and 
moderately good gingival health. DS was found to be common in the age group 3 - 9 years. Girls were seen to have a higher prevalence of DS compared to boys. Majority of the children had fair oral hygiene and moderate levels of gingivitis in the age group between 3 - 9 years. Therefore, it is advisable to promote oral hygiene practice in patients with Down syndrome at an early age to achieve good oral hygiene.

\section{Acknowledgement}

This research was supported by saveetha dental college and hospital. We thank the department of Pedodontics, Saveetha Dental College for providing insight and expertise that greatly assisted this research.

\section{References}

[1]. Lejeune J. Study of somatic chromosomes from 9 mongoloid children. CR Hebd Seances Acad Sci. 1959;248:1721-2

[2]. Hamerton JL, Briggs S, Giannelli F, Carter CO. Chromosome studies in detection of parents with high risk of second child with Down's syndrome. The Lancet. 1961 Oct 7;278(7206):788-91.

[3]. Cichon P, Crawford L, Grimm WD. Early-Onset Periodontitis Associated With Down's Syndrome-A Clinical Interventional Study. Ann Periodontol. 1998 Jul;3(1):370-80.

[4]. Arumugam A, Raja K, Venugopalan M, Chandrasekaran B, Kovanur Sampath $\mathrm{K}$, Muthusamy $\mathrm{H}$, et al. Down syndrome-A narrative review with a focus on anatomical features. Clin Anat. 2016 Jul;29(5):568-77.Pubmed PMID: 26599319

[5]. Abanto J, Ciamponi AL, Francischini E, Murakami C, de Rezende NP, Gallottini M. Medical problems and oral care of patients with Down syndrome: a literature review. Spec Care Dentist. 2011 Nov-Dec;31(6):197-203.Pubmed PMID: 22070358.

[6]. Macho V, Palha M, Macedo AP, Ribeiro O, Andrade C. Comparative study between dental caries prevalence of Down syndrome children and their siblings. Spec Care Dentist. 2013 Jan-Feb;33(1):2-7.Pubmed PMID: 23278142 .

[7]. Shore S, Lightfoot T, Ansell P. Oral disease in children with Down syndrome: causes and prevention. Community Pract. 2010 Feb 1;83(2):18-22.

[8]. Barkin RM, Weston WL, Humbert JR, et al. PHAGOCYTIC FUNCTION IN DOWN SYNDROME-I. CHEMOTAXIS. Journal of Intellectual Disability Research 2008; 24: 243-249.

[9]. Ram G, Chinen J. Infections and immunodeficiency in Down syndrome. Clin. Exp. Immunol. 2011 Apr;164(1):9-16

[10]. Borea G, Magi M, Mingarelli R, et al. The oral cavity in Down syndrome. J Pedod 1990; 14: 139

[11]. Altun C, Guven G, Akgun OM, Akkurt MD, Basak F, Akbulut E. Oral health status of disabled individuals attending special schools. Eur J Dent. 2010 Oct; $4(4): 361-366$.

[12]. Morgan J. Why is periodontal disease more prevalent and more severe in people with Down syndrome? Spec Care Dentist. 2007 Sep-Oct;27(5):196-201. Pubmed PMID: 17990479

[13]. Presson AP, Partyka G, Jensen KM, Devine OJ, Rasmussen SA, McCabe LL, et al. Current estimate of Down Syndrome population prevalence in the United States. J Pediatr. 2013 Oct;163(4):1163-8.Pubmed PMID: 23885965

[14]. Anders PL, Davis EL. Oral health of patients with intellectual disabilities: a systematic review. Spec Care Dentist. 2010 May;30(3):110-7.

[15]. Brown RH. A longitudinal study of periodontal disease in Down's syndrome. N Z Dent J. 1978 Jul;74(337):137-44.Pubmed PMID: 151813

[16]. Greene JC, Vermillion JR. The oral hygiene index: a method for classifying oral hygiene status. J Am Dent Assoc. 1960 Aug 1;61(2):172-9.

[17]. Löe $\mathrm{H}$. The gingival index, the plaque index and the retention index systems. J Periodontol. 1967 Nov;38(6):610-6

[18]. Khocht A, Janal M, Turner B. Periodontal health in Down syndrome: contributions of mental disability, personal, and professional dental care. Spec Care Dentist. 2010 May-Jun;30(3):118-23.Pubmed PMID: 20500707.

[19]. Khocht A, Yaskell T, Janal M, Turner BF, Rams TE, Haffajee AD, et al. Subgingival microbiota in adult Down syndrome periodontitis. J Periodontal Res. 2012 Aug; 47(4):500-7.Pubmed PMID: 22221039.

[20]. Bull MJ. Committee on Genetics. Health supervision for children with Down syndrome. Pediatrics 2011; 128: 393-406.
[21]. Rebelo MA, Queiroz AC. Gingival Indices: State of Art, Gingival DiseasesTheir Aetiology. Prevention and Treatment, Dr. Fotinos Panagakos (Ed.). 2011.

[22]. Pellegrini FP, Marinoni M, Frangione V, Tedeschi A, Gandini V, Ciglia F, et al.Down syndrome, autoimmunity and $\mathrm{T}$ regulatory cells. Clin Exp Immunol. 2012 Sep;169(3):238-43.Pubmed PMID: 22861363.

[23]. López-Pérez R, Borges-Yáńez SA, Jiménez-García G, Maupomé G. Oral hygiene, gingivitis, and periodontitis in persons with Down syndrome. Spec Care Dentist. 2002 Nov-Dec;22(6):214-20.Pubmed PMID: 12790229.

[24]. Al-Sufyani GA, Al-Maweri SA, Al-Ghashm AA, Al-Soneidar WA. Oral hygiene and gingival health status of children with Down syndrome in Yemen: A cross-sectional study. J Int Soc Prev Community Dent. 2014 May;4(2):826.Pubmed PMID: 25254190.

[25]. Kumar S, Sharma J, Duraiswamy P, Kulkarni S. Determinants for oral hygiene and periodontal status among mentally disabled children and adolescents. J Indian Soc Pedod Prev Dent. 2009 Jul-Sep;27(3):151-7.Pubmed PMID: 19841546

[26]. Oredugba FA. Oral health condition and treatment needs of a group of Nigerian individuals with Down syndrome. Downs Syndr Res Pract. 2007 Jul;12(1):72-6.Pubmed PMID: 17692192.

[27]. Hennequin M, Allison PJ, Veyrune JL. Prevalence of oral health problems in a group of individuals with Down syndrome in France. Dev Med Child Neurol. 2000 Oct;42(10):691-8.Pubmed PMID: 11085298.

[28]. Ahmed AN, Victor DJ. Identification of Tannerella forsythia and Treponema denticola in down syndrome subjects and healthy subjects with periodontal disease-A PCR study. Biomed. Pharmacol. J. 2018 Mar 25;11(1):525-30.

[29]. Jeevanandan G. Kedo-S Paediatric Rotary Files for Root Canal Preparation in Primary Teeth - Case Report. J Clin Diagn Res. 2017 Mar;11(3):ZR03ZR05.Pubmed PMID: 28511532.

[30]. Govindaraju L, Jeevanandan G, Subramanian EMG. Comparison of quality of obturation and instrumentation time using hand files and two rotary file systems in primary molars: A single-blinded randomized controlled trial. Eur J Dent. 2017 Jul-Sep;11(3):376-379.Pubmed PMID: 28932150.

[31]. Govindaraju L, Jeevanandan G, Subramanian EM. Knowledge and practice of rotary instrumentation in primary teeth among Indian dentists: a questionnaire survey. J Int Oral Health. 2017 Mar 1;9(2):45.

[32]. Somasundaram S, Ravi K, Rajapandian K, Gurunathan D. Fluoride Content of Bottled Drinking Water in Chennai, Tamilnadu. J Clin Diagn Res. 2015 Oct;9(10):ZC32-4.Pubmed PMID: 26557612.

[33]. Jeevanandan G, Govindaraju L. Clinical comparison of Kedo-S paediatric rotary files vs manual instrumentation for root canal preparation in primary molars: a double blinded randomised clinical trial. Eur Arch Paediatr Dent. 2018 Aug;19(4):273-278.Pubmed PMID: 30003514

[34]. Govindaraju L, Jeevanandan G, Subramanian E. Clinical Evaluation of Quality of Obturation and Instrumentation Time using Two Modified Rotary File Systems with Manual Instrumentation in Primary Teeth. J Clin Diagn Res. 2017 Sep;11(9):ZC55-ZC58.Pubmed PMID: 29207834.

[35]. Ravikumar D, Jeevanandan G, Subramanian EM. Evaluation of knowledge among general dentists in treatment of traumatic injuries in primary teeth: A cross-sectional questionnaire study. Eur J Dent. 2017 Apr;11(2):232-237.

[36]. Panchal V, Jeevanandan G, Subramanian E. Comparison of instrumentation time and obturation quality between hand $\mathrm{K}$-file, $\mathrm{H}$-files, and rotary Kedo-S in root canal treatment of primary teeth: A randomized controlled trial. J Indian Soc Pedod Prev Dent. 2019 Jan-Mar;37(1):75-79.Pubmed PMID: 30804311.

[37]. Packiri S, Gurunathan D, Selvarasu K. Management of paediatric oral ranula: a systematic review. J Clin Diagn Res. 2017 Sep;11(9):ZE06-ZE09.

[38]. Gurunathan D, Shanmugaavel AK. Dental neglect among children in Chennai. J Indian Soc Pedod Prev Dent. 2016 Oct 1;34(4):364.

[39]. Govindaraju L, Gurunathan D. Effectiveness of Chewable Tooth Brush in Children-A Prospective Clinical Study. J Clin Diagn Res. 2017 Mar:11(3):ZC31-ZC34.Pubmed PMID: 28511505.

[40]. Aishwarya A, Gurunathan D. Stress level in dental students performing pedodontic procedure. J Adv Pharm Educ Res. 2017;7(1).

[41]. Subramanyam D, Gurunathan D, Gaayathri R, Vishnu Priya V. Comparative evaluation of salivary malondialdehyde levels as a marker of lipid peroxidation in early childhood caries. Eur J Dent. 2018 Jan-Mar;12(1):67-70. Pubmed PMID: 29657527.

[42]. Ramakrishnan M, Bhurki M. Fluoride, Fluoridated Toothpaste Efficacy And Its Safety In Children-Review. Int. J. Pharm. Sci. Res. 2018 Oct $1 ; 10(04): 109-4$.

[43]. Nair M, Jeevanandan G, Vignesh R, Subramanian EM. Comparative evaluation of post-operative pain after pulpectomy with $\mathrm{k}$-files, kedo-s files and $\mathrm{m}$ two files in deciduous molars-a randomized clinical trial. Braz. Dent. Sci. 2018 Oct 24;21(4):411-7. 